\title{
Temporary social dumping, union legalisation and FDI: a note on the strategic use of standards
}

\author{
Dermot Leahy ${ }^{\dagger}$ and Catia Montagna \\ University College Dublin, Ireland; *University of Dundee, UK
}

\begin{abstract}
This paper analyses the welfare implications for a developing country of using union legalisation as a policy instrument to attract inward foreign direct investment. While its presence may discourage a foreign multinational (MNE) from locating in the host country, unionisation is an important rent-extracting instrument for the host country. We show that if the MNE benefits from dynamic effects, the host country government may have an incentive to adopt temporary social dumping: banning the union in the short run to extract higher rents in the future. However, if the government can use a fiscal instrument in conjunction with union legalisation, the former can circumvent the need to engage in social dumping.
\end{abstract}

\section{Keywords}

Multinationals, social dumping, labour standards

\section{INTRODUCTION}

A significant proportion of the discussion on globalisation, defined as an expansion of both cross-border transactions in goods and services and international capital flows, has centred on its effects on the labour markets. Low labour costs are often seen as a key factor in determining the ability of a country to compete for export markets and for foreign direct investment (FDI). Indeed, the growing importance of multinational enterprises (MNEs) in world markets signifies that the competitive pressure has, to an extent, shifted from firms themselves to workers in different countries bidding for their jobs with the same multinational firm.

Labour organisations in industrial countries typically fear that the increased competition from countries where labour standards are low, or not enforced, will lead to a 'race to the bottom', which will compromise labour standards in industrial countries as well. These fears are strengthened by the perceived

\section{Address for Correspondence:}

Department of Economics, University College Dublin, Belfield, Dublin 4, Ireland. e-mail: dermot.m.leahy@ucd.ie 
LDCs' governments' reticence to ratify and implement International Labour Conventions. Many LDCs have, in fact, shown opposition to the establishment of monitoring and enforcement mechanisms to their labour practices by the International Labour Organisation, ${ }^{1}$ worrying that the industrialised nations leading the charge for these mechanisms to be set up could use them as protectionist tools to dull developing nations' competitive advantages based on low labour costs. This suggests that, in particular in those regions which have to a great extent been bypassed by inward FDI flows (such as Africa and South-Asia), governments may strategically choose to repress unionisation and to pursue low labour standards in their attempt to preserve, and/or enhance, their competitiveness in goods and FDI markets.

The aim of this paper is to explore the possibility of the strategic use of labour standards by a developing country's government trying to attract inward FDI. To our knowledge, this paper is the first to examine the strategic use of labour standards as a policy instrument.

In the emerging literature on labour standards and international trade, even when endogenously determined - as for example in Casella (1996) and Srinivasan (1996) - standards are not treated as a policy variable. Similarly, the relatively small but growing literature that explores the relationship between labour market unionisation and FDI ignores the possibility of the government's strategic use of union legislation. ${ }^{2}$

To start addressing the issue of the optimal use of labour standards as trade policy instruments, we construct a simple model in which a developing country's government makes strategic use of labour union legalisation to influence the optimal behaviour of a foreign multinational that may potentially locate in the country. The model does not aim at providing an exhaustive analysis of the optimal use of standards to attract FDI, but rather to highlight the nature of some of the factors affecting a government's economic incentives to regulate unionisation.

Leaving aside political economy considerations, unions may generate a trade-off for the host country's government. ${ }^{3}$ On the one hand, they represent an important means of rent extraction. A Multinational Enterprise (MNE) will typically hold firm specific 'rent-yielding assets' (Caves, 1996) and the prospect of rent shifting may thus be attractive to both the host country government and unions. ${ }^{4}$ On the other hand, a 'union free environment', which is typically associated with lower wages, may be seen as useful by the host country's government in its attempt to attract and retain MNEs' investment. ${ }^{5}$

In this paper we allow for the possibility that the MNE benefits from dynamic effects such as, for example, consumer switching costs, brand loyalty and learning by doing. In this context, the host government may have an incentive to subsidise temporarily the MNE in order to enhance future potential rent-extraction. One, indirect, way of doing this may be through 'social dumping': banning the union in the short run may yield greater rents in the long run.

The paper is organised as follows. Section 2 sets out the basic model and 
discusses the optimal policy with respect to union legalisation. In Section 3, a jointly optimal policy mix in which the government has the use of a subsidy/ tax instrument is analysed. Section 4 draws some conclusions.

\section{THE BASIC MODEL}

To examine these issues, we use a very simple two-period partial equilibrium model. We assume there is one multinational that is considering setting up in this developing economy to serve export markets. The MNE uses local labour but does not sell in the local market. No host country firms compete with the foreign multinational. ${ }^{6}$ The two periods are linked through dynamic economies of scale, in the sense that a higher first period output raises the firm's second period profits.

The host country's government, which in principle would like to attract the foreign firm, faces the dilemma of whether or not to legalise unions. At the beginning of each period, the government decides whether to allow unions or not for that period. In this section, we shall assume that the government does not have subsidy/tax instruments at its disposal and it is only able to decide whether to allow the union or not. This assumption, is relaxed in the next section.

Unions are assumed to maximise total labour rents by choice of the union wage. We ignore issues arising from the relative bargaining power of unions and firms. Different relative bargaining powers of unions and employers are not central to our concerns in this paper and would complicate the analysis without yielding many additional insights. We also assume a right-to-manage model, where firms decide on the level of output.

Thus, the model has two periods and consists of a dynamic game between three players, the host country's government, the union, and the foreign multinational. We shall allow for the possibility that both the government and the multinational may take a longer term view than the labour unions, whose main preoccupation may be short-term wage increases and recognition. We shall also consider the case in which the union's rate of time preference is the same as that of the government, and we shall compare the implications of this alternative assumption for government policy towards unions.

In each period, the government first decides whether unions should be legalised or not for the remainder of that period. In period one, following the government decision about union legalisation, the MNE decides whether to locate in the host country or not. We assume that once the MNE sets up in the home country, it stays for the remainder of the game. We thus rule out any relocation threat: if the MNE enters, it does not leave in period two. ${ }^{7}$ If unions exist, they decide on the wage in each period in order to maximise total union rents. Finally, in each period the MNE chooses its output.

In period $t(t=1,2)$ the demand function of the MNE in its export market is: 


$$
q_{t}=a_{t}-p_{t}
$$

The MNE faces marginal cost $c_{t}$ that is constant in its current output.

In order to introduce a dynamic link between period one output and period two profits, it proves useful to write the gap between the demand intercept and the marginal cost as:

$$
a_{t}-c_{t}=A_{t}-\omega_{t}+\beta q_{t-1}>0
$$

where $A_{t}$ is a period specific constant, $\beta$ is a positive constant and $\omega_{t}$ is period $t$ wage. This is the simplest way of introducing beneficial dynamic effects, which could arise on the demand side and/or on the cost side as a result of consumers' switching costs, brand loyalty, experience effects and distributional scale economies, amongst other things. We shall further assume that the MNE has a unit labour requirement, that is $l_{t}=q_{t}$ where $l_{t}$ is the labour employed by the multinational in the home country.

Note that $A_{t}$ can be seen as reflecting market size. Let $\alpha=A_{2} / A_{1}$ capture the evolution of $A_{t}$ over time. Clearly, $\alpha$ will affect the host country's rent extraction potential from the MNE. If $\alpha<1$, the extent of the market facing the MNE is shrinking over time, as will happen in a declining industry.

\subsection{Period two}

Period two begins with the government deciding whether to legalise the union for the period. If legal, the union then chooses the wage. Finally, the MNE chooses the second period output. The multistage game is solved in the usual way by backward induction.

In the final stage of the second period, the MNE maximises period-two profit $\left(p_{2}-c_{2}\right) q_{2}$. The optimal output level is given by:

$$
q_{2}=\frac{A_{2}-\omega_{2}+\beta q_{1}}{2}
$$

If the union does not exist, the wage paid by the MNE will be $\omega_{2}=\bar{w} \geq 0$. Without loss of generality, we normalise the wage outside the multinational sector at zero. Hence, we assume that $\bar{w}$, the wage in the absence of a union, is not less than the opportunity cost of labour in the country. If $\bar{w}>0$ then even a non-unionised multinational pays wages above the opportunity cost of labour. This is a reasonable assumption, which conforms to the evidence of MNEs paying higher wages than domestic firms (Caves, 1996). Let the union wage be $\omega_{t}=w_{t}$. We are assuming that employment and wages have the same weight in the unions' utility function. One could allow for different weights and this would raise other interesting considerations that are not, however, central to the aims of this paper. If the union exists in the second period, then anticipating the relationship in equation (3) it chooses the union wage $w_{2}$ to maximise its 
second period labour rent $w_{2} q_{2}$. If the union does not exist, the labour rents are $\bar{w} q_{2}(\bar{w})$. Note that the union does not maximise $\left(w_{2}-\bar{w}\right) q_{2}$ because the wage workers would get if not employed by the MNE is zero and not $\bar{w}$ (the wage the MNE would pay if there were no union). Hence, the union will solve the following problem:

$$
\operatorname{Max}_{w_{2}} w_{2} q_{2} \text { s.t. } \quad w_{2} \geq \bar{w}
$$

If this constraint binds, the presence of the union is irrelevant to the wage determination, so for this reason we will assume that it never binds. In this case, the equilibrium union wage is:

$$
w_{2}=\frac{A_{2}+\beta q_{1}}{2}
$$

The second period equilibrium output will then be given by:

$$
q_{2}=\left\{\begin{array}{lll}
\left(A_{2}+\beta q_{1}\right) / 4 & \text { if } & \omega_{2}=w_{2} \\
\left(A_{2}-\bar{w}+\beta q_{1}\right) / 2 & \text { if } & \omega_{2}=\bar{w}
\end{array}\right.
$$

At the beginning of period two, the government chooses whether to legalise the union or not. Assuming that all profits are repatriated, and in the absence of domestic consumption, the government's social welfare function is given by

$$
G=\omega_{1} q_{1}+\rho^{g} \omega_{2} q_{2}
$$

where $\rho^{g}$ is the government's discount factor. It is plausible to assume that the government may not be able to commit in period one to its policy in period two. In this case, in period two the government maximises the function $G_{2}=\omega_{2} q_{2}$, which is equivalent to the union's objective function in period two. ${ }^{8}$ Hence, $G_{2}$ is maximised by the same value of $w_{2}$ that is chosen by the union and given in equation (5). Therefore, assuming the government cannot commit at the beginning of period one to ban the union in period two, and given no relocation threat, the best policy in period two is always to legalise the union.

\subsection{Period one}

In the last stage of period one, the MNE chooses the first period output to maximise the intertemporal profit function:

$$
\pi=\left(p_{1}-c_{1}\right) q_{1}+\rho^{m}\left(p_{2}-c_{2}\right) q_{2}
$$

where $\rho^{m}$ is the MNE discount factor. It is straightforward to solve the MNE's optimal problem to find: 


$$
q_{1}=\frac{A_{1}\left(1+\alpha \rho^{m} \beta / 8\right)-\omega_{1}}{\left(2-\rho^{m} \beta^{2} / 8\right)}
$$

Note that the first period output is increasing in $\alpha$, in the discount factor $\rho^{m}$ and in the dynamic returns to scale parameter $\beta$. The larger these parameters, the greater the incentive the MNE has to produce above the short-run profit maximising amount to exploit the higher discounted profit opportunity of the second period.

If there is no union, then the MNE's wage will be $\omega_{1}=\bar{w}$. However, if the union is legalised in period one, it will optimally choose the wage to maximise its objective function. It is plausible that the union has a discount factor that is smaller than that of both the government and the MNE. We shall discuss later the implications of the case in which $\rho^{u}=\rho^{g}$. First, we will consider the case in which the union is more impatient than the government. Without too much loss of generality, we shall assume that the union's discount factor is zero ${ }^{9}$ (i.e. $\rho^{u}=0$ ). Thus, its utility function is $U_{1}=w_{1} q_{1}$ and the optimal wage will be given by:

$$
w_{1}=\frac{A_{1}\left(1+\alpha \rho^{m} \beta / 8\right)}{2}
$$

Note that the first period union wage is also increasing in $\alpha, \beta$ and $\rho^{m}$. The more the firm produces in the first period to exploit future profit potential, the larger are the available short-run rents that can be extracted by the union. Hence, whether or not the multinational's export market is contracting or expanding over time will crucially affect the available labour rents in period one.

Period one output can now be re-written as:

$$
q_{1}= \begin{cases}{\left[A_{1}\left(1+\alpha \rho^{m} \beta / 8\right)-\bar{w}\right] /\left(2-\rho^{m} \beta^{2} / 8\right)} & \text { if } \omega_{1}=\bar{w} \\ A_{1}\left(1+\alpha \beta \rho^{m} / 8\right) /\left(4-\rho^{m} \beta^{2} / 4\right) & \text { if } \omega_{1}=w_{1}\end{cases}
$$

It is easy to show that the maximised profit of the MNE is:

$$
\pi=q_{1}^{2}+\rho^{m} q_{2}^{2}-\rho^{m} \beta q_{1} q_{2}
$$

where $q_{1}$ is given by (11); making use of (9) in (6) and invoking the fact that it is always optimal to legalise the union in period two, $q_{2}$ becomes:

$$
q_{2}=\frac{A_{1}\{2 \alpha+\beta\}-\beta \omega_{1}}{8-\rho^{m} \beta^{2} / 2}
$$

The MNE will enter if $\pi>\bar{\pi}$, where $\bar{\pi}$ reflects outside profit opportunities which we take as exogenous. This is a standard small open economy 
assumption. Given that both $q_{1}$ and $q_{2}$ are ultimately only a function of $\omega_{1}$, the MNE entry condition can be written as:

$$
\pi\left(\omega_{1}\right)-\bar{\pi}>0
$$

where it is straightforward to show that $\frac{d \pi}{d \omega_{1}}<0$. Thus, the higher is the first period wage, the lower is the present value of the MNE's profit. Let $\hat{w}(\bar{\pi})$ be the wage rate at which $\pi=\bar{\pi}$. Then, in period one the MNE would not enter in the presence of a union if $w_{1} \geq \hat{w}$. If, instead, $w_{1}<\hat{w}$ the presence of a union would not deter the MNE's entry. Figures 1 and 2 illustrate these two possible entry scenarios.

There is, of course, the possibility that $\bar{w} \geq \hat{w}$. In this case, the MNE will never find it profitable to enter, even without a union in period one.

In general, the more intense is competition in the world market for FDI, the higher is the reservation profit, and the less likely is entry with a union.

We now turn to stage one of the game where the government chooses the period-one union legislation. The government's objective function will be:

$$
G\left(\omega_{1}\right)=U_{1}\left(\omega_{1}\right)+\rho^{g} U_{2}\left(\omega_{1}\right)
$$

Unconditional maximisation of this function would set the socially optimal wage for period one. Note that if the union had the same discount rate as the government it would maximise the function in (15); in this case, the union

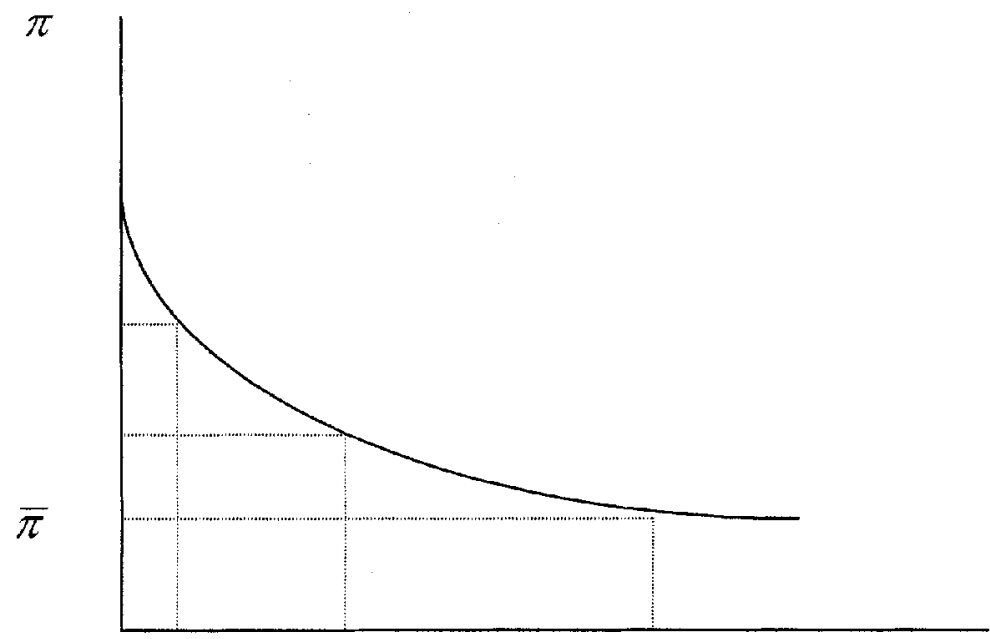

$\bar{w}$ $w_{1}$ $\hat{w}$

Figure 1 The case where the MNE will enter in the presence of a period one union 


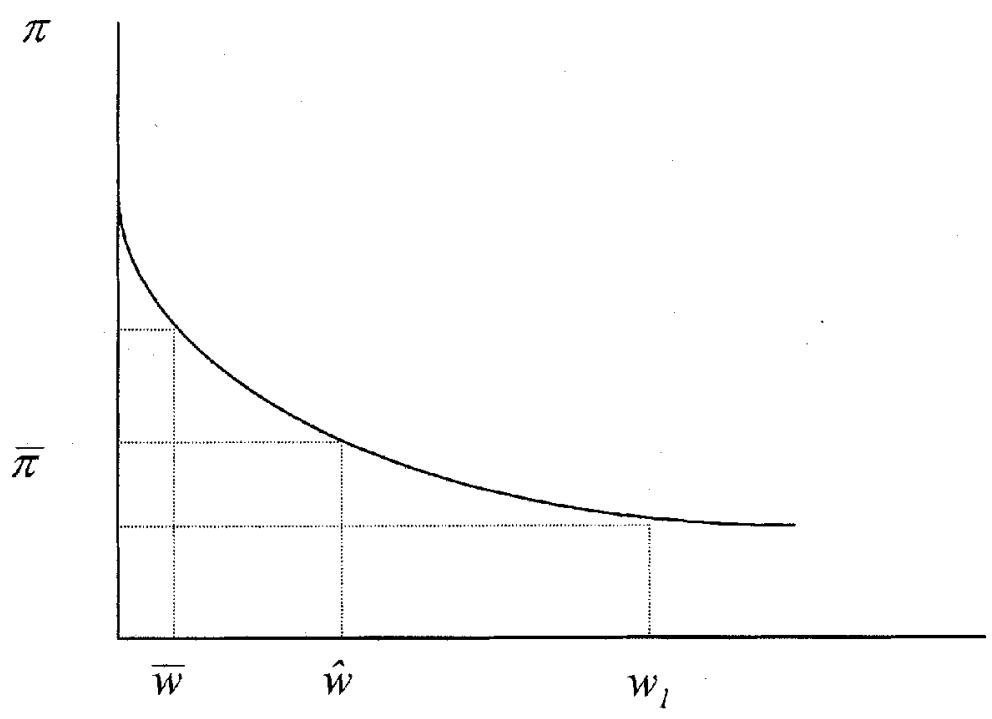

$\omega_{1}$

Figure 2 The case where the MNE will not enter in the presence of a period one union

wage would be socially optimal. Instead, when the union is more impatient than the government, the wage it will choose will be above the optimal level from the government's point of view.

The function in (15) is concave in $\omega_{1}$ and will depend on the magnitude of the structural parameters of the model ( $\alpha, \beta$, and the discount factors). $\bar{w}$ is exogenous and $\hat{w}$ is inversely related to $\bar{\pi}$. The ranking in order of magnitude of $\bar{w}, \hat{w}$ and $w_{1}$ will be crucial to determining optimal union legislation policy. The decision regarding union legalisation in period one depends not only on the magnitude of the MNE's reservation profit (or $\hat{w}$ ), but also on the magnitude of $\bar{w}$ (the wage that MNE pays in the absence of a union). Two cases can be identified.

\section{Case 1}

When welfare is higher at $\omega_{1}=\bar{w}$ than at $\omega_{1}=w_{1}$, that is when $G(\bar{w})>G\left(w_{1}\right)$, the government will find it optimal to ban the union. In this case, the decision to ban is independent of the size of $\hat{w}$ (and hence of the size of the MNE's reservation profits); the government would ban the union even if the MNE would enter with unionisation in period one. This case is illustrated in Figure 3, where $\tau$ is implicitly defined by $G(\tau)=G\left(w_{1}\right)$ and $\tau<w_{1}$.

Case 1 obtains if $\bar{w}$ lies in the interval between $\omega_{1}=\tau$ and $\omega_{1}=w_{1}$.

\section{Case 2}

When welfare is at least as high at $\omega_{1}=w_{1}$ as it is at $\omega_{1}=\bar{w}$, that is $G(\bar{w})$ $\leq G\left(w_{1}\right)$, two sub-cases emerge. In the first (Case 2.1) $w_{1} \geq \hat{w}$ and the government will find it optimal to ban the union because, with a union, the 


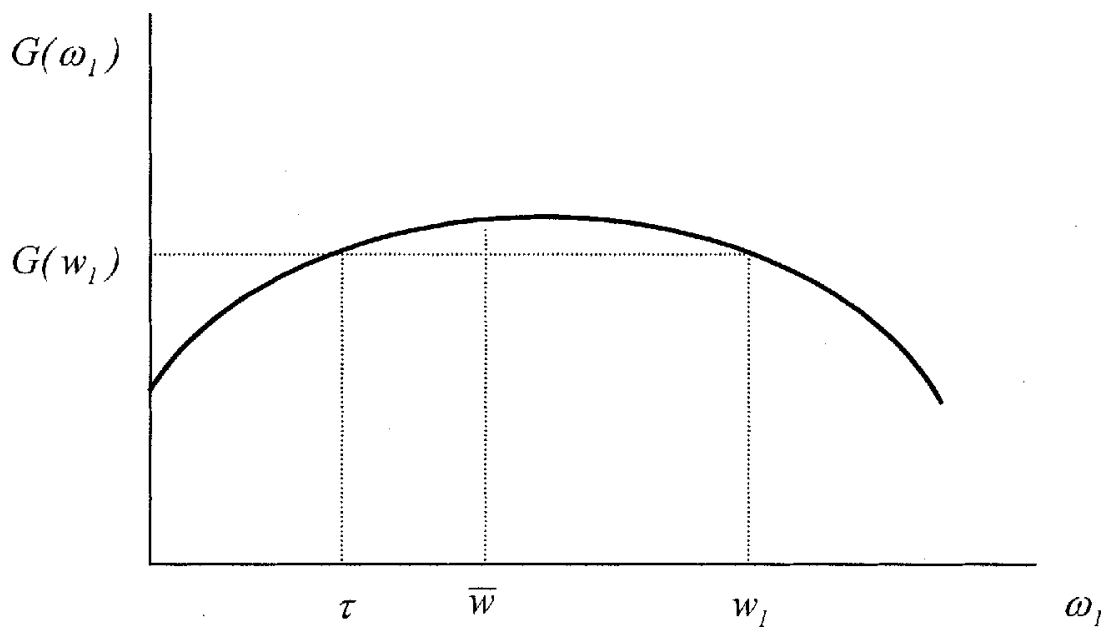

Figure 3 Case 1: $G(\bar{w})>G\left(w_{1}\right)$. Not optimal for the Government to legalise period one union

MNE would not enter. ${ }^{10}$ This sub-case is illustrated in Figure $4 .{ }^{11}$ In the second sub-case (Case 2.2), illustrated in Figure $5, w_{1}<\hat{w}$ and the government will find it optimal to legalise the union if $G(\bar{w})<G\left(w_{1}\right)$ and be indifferent if $G(\bar{w})$ $=G\left(w_{1}\right)$.

In both Cases 1 and 2 above, illustrated in Figures 3 to $5, w_{1}$ is to the right of the maximum point on the $G\left(\omega_{1}\right)$ curve. This reflects the assumption that the union has a lower discount factor than the government. If it did have the same

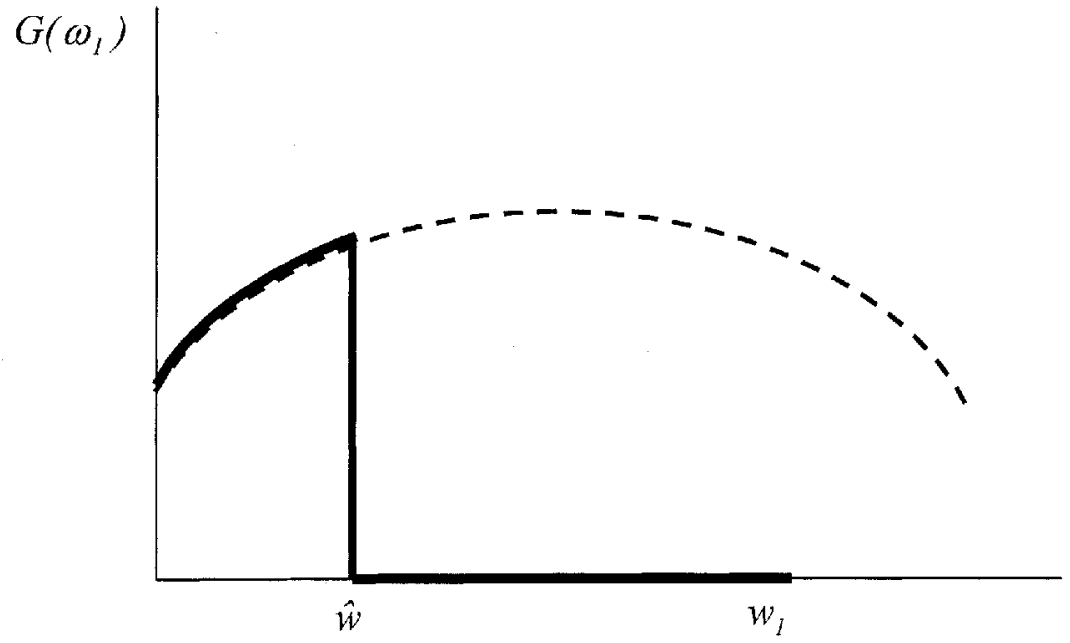

Figure 4 Case 2.1: $G\left(w_{1}\right) \geq G(\bar{w})$ and $w_{1} \geq \hat{w}$. Not optimal for the Government to legalise period one union 


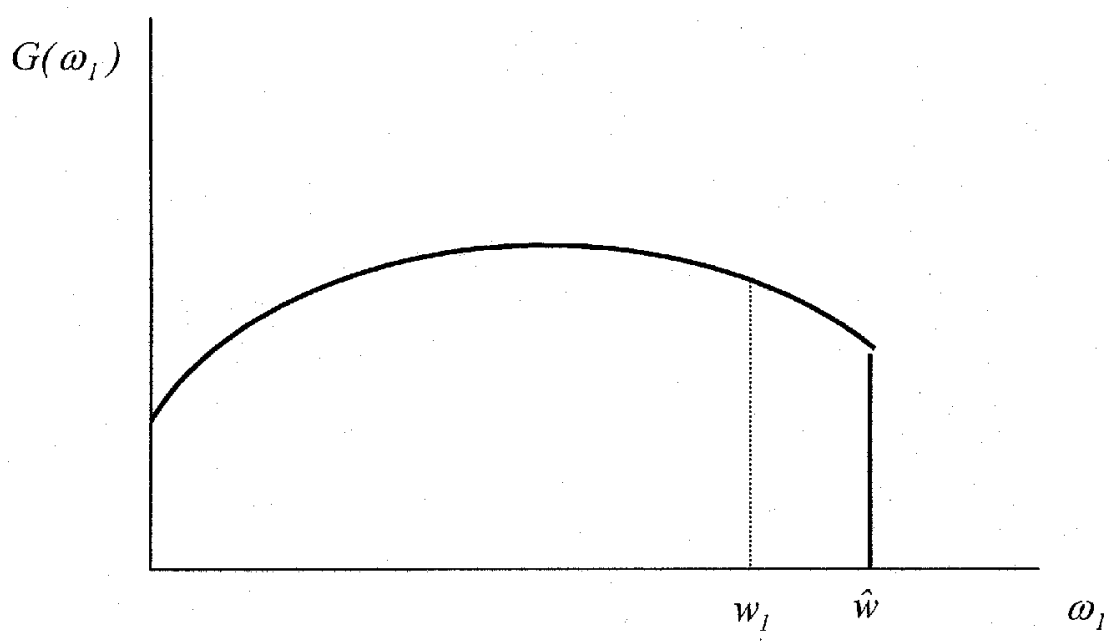

Figure 5 Case 2.2: $G\left(w_{1}\right) \geq G(\bar{w})$ and $w_{1}<\hat{w}$. Optimal for the Government to legalise period one union

discount factor as the government, $w_{1}$ (the wage chosen by the union) would maximise $G\left(\omega_{1}\right)$. In that instance, Case 1 would not apply because the interval between $\tau$ and $w_{1}$ would disappear. Case 1 , in which it is optimal to ban the union because $G(\bar{w})>G\left(w_{1}\right)$, can occur only if there is a 'time preference differential' between the union and the government. Note, however, that when there is no difference in the time preference parameters, that is when $\rho^{u}=\rho^{g}$, there will still be a case for banning the union if $w_{1} \geq \hat{w}$. Clearly, this motive for banning the union is due to a 'time consistency' problem which stems from the sequence of the game, with the MNE having to make its location decision before the union sets the wage. ${ }^{12}$ Hence, a time consistency problem would always arise when $w_{1} \geq \hat{w}$, regardless of whether or not the union has the same discount factor as the government. Thus, although it is more likely when the union is more impatient than the government, temporary social dumping can occur even when no difference in time preference exists between the government and the union.

We carried out some simulation exercises on the model. For the parameter values $A_{1}=\alpha=1, \beta=0.2, \rho^{g}=\rho^{m}=1$ and $\rho^{u}=0$, we found ${ }^{13}$ that $w_{1}$ is approximately 0.51 which is above the value of $\omega_{1}$ (of approximately 0.485 ) which maximises $G\left(\omega_{1}\right)$. For these parameter values, we found that $\tau$ is about 0.46 . For $\bar{\pi}$ above approximately 0.12 , we get $\hat{w}>w_{1}$ (as in Figures 1 and 5), and for $\bar{\pi}$ lower than this gives $\hat{w}<w_{1}$ as in the case of Figures 2 and 4 . From these simulations we learn that (1) each of the above cases can occur, but (2) the interval $\left(\tau, w_{1}\right)$ is very small, so that Case 1 will only be observed for a very narrow range of parameter values, and (3) $w_{1}$ is very close to the level of $\omega_{1}$ that maximises $G\left(\omega_{1}\right)$. Hence, somewhat surprisingly, even a big difference between the discount factor of the government and that of the union does not 
lead to the wage set by the union being very far from the socially optimal wage.

Clearly, the nature of the optimal policy towards the legalisation of the union in period one of the game crucially depends, ceteris paribus, on the magnitude of the MNE's reservation profit that is taken to be exogenous in this model. Several factors may be thought to affect the reservation profits of the MNE. For example, the outside profit of the MNE will be positively related to the availability of other potential FDI destinations characterised by favourable conditions, as for instance low labour costs and/or lack of unionisation. If the multinational's choice of the host country reflects geographical proximity considerations to third market destinations, then the reservation profit will also be affected by the reduction of transport costs and other barriers to trade that may reduce the incentive of the MNE to invest abroad and may make it more profitable to serve foreign markets from the home country.

\section{PRODUCTION SUBSIDIES}

So far, we have assumed that the only policy available to the government is union legislation. A more direct way of attracting the multinational, however, would be through the use of a fiscal policy instrument such as, for example, a production subsidy. In this section we allow for the use of both production subsidies and union legislation, and derive the jointly optimal policy mix. Our aim is to discuss how the availability of a fiscal instrument affects the government's optimal choice about union legalisation.

The profit function in (8) is thus modified and is now given by:

$$
\pi=\left(p_{1}-c_{1}+s_{1}\right) q_{1}+\rho^{m}\left(p_{2}-c_{2}+s_{2}\right) q_{2}
$$

It is straightforward to show that the second period output is:

$$
q_{2}=\left\{\begin{array}{lll}
\frac{A_{2}+\beta q_{1}+s_{2}}{4} & \text { if } \omega_{2}=w_{2} \\
\frac{A_{2}-\bar{w}+\beta q_{1}+s_{2}}{2} & \text { if } \quad \omega_{2}=\bar{w}
\end{array}\right.
$$

which collapses to (6) when $s_{2}=0$. The second period wage is now given by:

$$
\omega_{2}= \begin{cases}w_{2}=\frac{A_{2}+\beta q_{1}+s_{2}}{2} & \text { with union } \\ \bar{w} & \text { without union }\end{cases}
$$

As before, we assume that the non-union wage is $\bar{w}$ smaller than $w_{2}$.

In either case, the government maximises: 


$$
G_{2}=\left(\omega_{2}-s_{2}\right) q_{2}
$$

to yield the optimal subsidy:

$$
s_{2}^{o}= \begin{cases}0 & \text { for } \omega_{2}=w_{2} \\ \bar{w}-\frac{A_{2}+\beta q_{1}}{2} & \text { for } \omega_{2}=\bar{w}\end{cases}
$$

With a union in period two, the optimal policy would be not to tax/subsidise the MNE. In the absence of a union and when $0 \leq \bar{w}<w_{2}$, we get $s_{2}^{o}<0$, that is the optimal policy is a tax. Now, making use of (20) in (17), we get the output level:

$$
q_{2}=\frac{A_{2}+\beta q_{1}}{4}
$$

Clearly, period two output is the same with and without a union. This means that the production tax compensates for the existence of the union and can be used to reach the same real equilibrium. The reason for this is that the tax/ subsidy instrument is a perfect rent extracting substitute for the union. From (18) and (20) it is straightforward to show that the per-unit rent extracted, i.e. the equilibrium wage net of subsidy, is the same with or without a union. That is $\omega_{2}-s_{2}^{o}=\left(A_{2}+\beta q_{1}\right) / 2$.

The second period welfare level will, therefore, be rewritten as $G_{2}=2 q_{2}^{2}$, which from (21) is the same both with and without a union. This implies that, given our simple utilitarian welfare function, the same welfare level is achieved under both union regimes. If there is no relocation threat, and the government can use a fiscal instrument to extract rents from the multinational, the union regime in period two is no longer crucial.

In period one, the MNE maximises the function in (16) to get the output level:

$$
q_{1}=\frac{A_{1}\left(1+\alpha \rho^{m} \beta / 8\right)-w_{1}+s_{1}}{\left(2-\rho^{m} \beta^{2} / 8\right)}
$$

Assuming $\rho^{u}=0$, the wage in period one will be:

$$
\omega_{1}= \begin{cases}w_{1}=\frac{A_{1}\left(1+\alpha \rho^{m} \beta / 8\right)+s_{1}}{2} & \text { with union } \\ \bar{w} & \text { without union }\end{cases}
$$

In stage 1, the government decides its union legalisation and sets its subsidy $s_{1}$. As in the previous section, it may face a binding foreign profit constraint. As a prelude to the constrained optimal case, let us consider the special case in 
which the multinational's entry profit constraint is not binding. The government then maximises the following unconstrained intertemporal welfare function:

$$
G=\left(\omega_{1}-s_{1}\right) q_{1}+2 \rho^{g} q_{2}^{2}
$$

It is straightforward to show that the optimal subsidy is:

$$
s_{1}^{o}=\omega_{1}-\left[2-\rho^{m} \frac{\beta^{2}}{8}-\rho^{g} \frac{\beta^{2}}{4}\right] q_{1}+\rho^{g} \frac{\beta}{4} \alpha A_{1}
$$

Equation (25) holds for both union legalisation regimes, with the appropriate $\omega_{1}$ given in equation (23) above. Substituting from (23) and rearranging yields the unconstrained optimal subsidy with a union $s_{1}^{u}$ and without a union $s_{1}^{n}$, which are respectively given by:

$$
s_{1}^{u}=\frac{\rho^{g} \beta\left(\alpha A_{1}+\beta q_{1}\right)}{4}>0
$$

and

$$
s_{1}^{n}=s_{1}^{u}-\left(w_{1}-\bar{w}\right)
$$

Notice that there are two effects in determining the sign of the first period subsidy. First, with or without the union, the government has an incentive to subsidise the MNE to encourage it to exploit its dynamic economies of scale in order to raise employment and rents over the two periods. This is captured by equation (26), which is also the first term of (27). Note that this will be zero if the government had the same degree of impatience as the union. The second effect occurs in the absence of a union and captures the incentive of the government to extract rent directly. This effect works towards a tax and is captured by the second term on the right-hand side of (27).

To summarise, optimal subsidies tend to fall through time. With a union legalised in both periods, it is optimal to subsidise in period one but to set the second period subsidy equal to zero. Without a union it may be optimal to subsidise in the first period but it will always be optimal to tax in period two.

It proves useful to consider the 'first-period per-unit rent', defined as $\delta_{1}=\omega_{1}-s_{1}$, which gives us a measure of the rent extracted (i.e. the wage net of subsidy) by the country from the MNE in that period. Hence, we can think of the optimal policy as one of choosing the optimal per-unit rent. The firstperiod optimal policy can then be re-written as

$$
\delta_{1}^{o}=\omega_{1}-s_{1}^{o}=w_{1}-s_{1}^{u}
$$

It is clear from (28) that, given the union legislation, the optimal policy can be thought of as choosing the 'first-period per-unit rent' in order to maximise the welfare function in (24). Clearly, we would expect that the amount of rent that can be extracted will be less if the government has to take account of a binding 
entry constraint. When the MNE's profit constraint is binding, the government optimisation problem will be to maximise the Lagrangian

$$
L\left(\delta_{1}, \lambda\right)=\delta_{1} q_{1}\left(\delta_{1}\right)+2 \rho^{g}\left(q_{2}\left(\delta_{1}\right)\right)^{2}+\lambda\left(\pi\left(\delta_{1}\right)-\bar{\pi}\right)
$$

to yield

$$
\delta_{1}^{c}=\left(2-\rho^{m} \frac{\beta^{2}}{8}-\rho^{g} \frac{\beta^{2}}{4}\right) q_{1}-\rho^{g} \frac{\beta}{4} \alpha \mathrm{A}_{1}+\left(2-\rho^{m} \frac{\beta^{2}}{8}\right) \lambda \pi^{\prime}\left(\delta_{1}\right)
$$

where $\delta_{1}^{c}$ is defined as the constrained optimal first-period per-unit rent. It is straightforward to show that equation (30) implies a higher level of subsidisation than in the unconstrained case. It is also easy to show that an increase in the MNE's reservation profit reduces the ability of the home country to extract rent.

It is clear that welfare is the same with or without the union, because the government will use the subsidy to correct for the presence of the union. The equality of the welfare outcomes across union regimes then implies that, even in period one, union legalisation is no longer the crucial factor in the attempt to attract FDI. This goes against the popular perception that unionisation is a major deterrent of FDI.

Clearly, the simple welfare function we use takes no explicit account of political economy considerations that may be particularly relevant in a developing economy setting. These may include international pressure to legalise unions, dead-weight costs associated with raising taxation, and inefficient activities such as government corruption. Note, however, that to the extent that these factors are important, they may bias the decision in favour of union legalisation. Essentially, there are two ways of extracting rent from the MNE: taxes and higher wages. If, for example, the public administration suffers from high levels of inefficiencies and corruption, then higher wages may have an advantage over taxation in that the extracted rents go directly into the hands of the private sector. Of course, governments may have other political motives for banning unions, but these are unlikely to be welfare increasing. Also, a policy based on production subsidy may be difficult, if raising the funds to finance it imposes a dead-weight cost on society. If a production subsidy could only be used with a positive social cost of funds, then it will not be a perfect substitute for union legislation. If the social cost of funds was prohibitively high, so that a production subsidy could not be used, the relevance of the analysis of Section 2 would be strengthened.

Finally, note that if the government could control the union, as in the case of an official state union, then it could set the wage $w_{1}=\delta_{1}$ before the MNE enters, thus rendering production subsidies redundant, although even in this case, time consistency issues may arise. 


\section{CONCLUSIONS}

In this paper we have explored the strategic use of labour union legalisation by a developing country's government concerned with attracting inward FDI.

We show that when considering whether to legalise the unions or not, the host country government faces a trade-off. On the one hand, unions represent an attractive tool for rent extraction in the presence of foreign multinationals. On the other hand, however, unionisation can make the location in the host country less attractive to the foreign investor. This trade-off raises the incentive for the host country government to use temporary social dumping in the form of restricted union rights.

Another of our results shows that production subsidies can circumvent the need to engage in this form of social dumping. That is, if the government has another fiscal instrument at its disposal, union legalisation is no longer a crucial factor in attracting inward FDI. This result goes against the popular perception that unionisation is a major deterrent of FDI.

A production subsidy is a direct way of raising employment, but another policy instrument that could be considered is lump-sum profit subsidies/taxes. If the government can use both of these fiscal instruments, then it would set the after-tax profit of the multinational just equal to the latter's reservation profit, thus ensuring inward FDI and at the same time extracting all available rent. The outcome would be independent of union legislation, in line with our result in Section 3.

In this paper, the focus was on the possibility of temporary, rather than permanent, social dumping. Although the temporary aspect clearly requires us to use a multi-period model, optimal social dumping per se could, of course, emerge in other settings, including single-period ones. For example, intratemporal positive externalities between the MNE and the rest of the local economy may also create such an incentive.

One could extend the model in a number of ways. For example, the inclusion of an export oriented domestic sector would allow for the modelling of one of the main attractions of inward FDI for developing countries, namely the positive technological externalities from foreign MNEs to the domestic economy. Such externalities, however, are likely to strengthen the case for temporary social dumping, since they would make inward FDI more attractive to the host country's government. Hence, this would be unlikely to alter significantly the basic insights of the current model. Also, the model developed here rules out, by assumption, the possibility of MNE's relocation. Clearly, a relocation threat is a reality in many industries, particularly those characterised by relatively low set up and relocation costs. Relocation, by strengthening competition between countries, would make the danger of a 'race to the bottom' in labour standards more likely, thus increasing an LDC's government incentives for social dumping. Explicitly allowing for this in this framework would be fairly straightforward and would probably have fairly obvious implications. 


\section{ACKNOWLEDGEMENTS}

The authors would like to thank Sajal Lahiri, Wolfgang Mayer, Hassan Molana, Pascalis Raimondos-Moller, Sheila Paige, participants at the Second CRIE Conference at Middlesex University and seminar participants at the Economic Policy Research Unit, University of Copenhagen, and two anonymous Referees for useful comments. The usual disclaimer applies.

\section{NOTES}

1 The 86th International Labour Conference (June 1998) has adopted a Declaration on Fundamental Principles and Rights at Work, committing ILO's members to uphold fundamental rights in the workplace (freedom of association, right to collective bargaining, progressive elimination of forms of forced labour, child labour and discrimination).

2 See Zhao $(1995,1998)$ for the emergence of cross-hauling FDI between two unionised countries. Naylor and Santoni (1998) analyse the effects of union power and degree of substitutability between products on FDI. Leahy and Montagna (2000) investigate the effects of different degrees of wage setting centralisation on the investment and location decisions of a MNE.

3 Although the presence of unions may raise political economy considerations, we shall use the standard assumption that the government is a benevolent national welfare maximiser.

4 Katrak (1977) and Brander and Spencer (1981) analyse the use of rent-extracting tariffs in the presence of a foreign monopoly selling in the domestic market. Bughin and Vannini (1995) and Leahy and Montagna (2000) explore the relationship between unionisation and rent extraction from a foreign multinational.

5 On balance, governments see inward FDI as desirable, even in the absence of union rent extraction. MNEs are seen as a source of employment and will typically pay higher wages than local firms even in the absence of unionisation, due perhaps to efficiency wage considerations or other factors. Additionally, MNEs are seen as generating positive technological externalities, and procompetitive effects on industry.

6 Leahy and Montagna (2000) analyse direct product market competition between a foreign multinational and domestic firms in the presence of rent extracting unions.

7 This would be typical of an industry characterised by high sunk costs of entry, such as oil refining and extraction.

8 As shown in the next section, this would be modified if the government had a production tax/subsidy instrument.

9 Qualitatively, the results will go through for all $\rho^{u}<\rho^{g}$. For ease of exposition we focus on the case of $\rho^{u}=0$.

10 Of course, if $\bar{w} \geq \hat{w}$ then even banning the union would be insufficient to induce entry of the MNE.

11 In the figure, $\hat{w}$ is shown on the upward sloping portion of $G\left(\omega_{1}\right)$, but clearly in Case 2.1 it could be elsewhere on the curve, provided that $w_{1} \geq \hat{w}$.

12 For this move order to be reversed, we would require the union to commit in advance to a wage for an unrealistically long time. Clearly, any wage set before the MNE's entry is likely to be sub-optimal because it would be based on a guess about the future profitability of the MNE. Hence, we believe the sequence chosen is by far the most plausible.

13 The qualitative results are quite robust with respect to changes in these parameter values. 


\section{REFERENCES}

Brander, J. and Spencer, B. (1981) 'Tariff and the extraction of foreign monopoly rents under potential entry'. Canadian Journal of Economics 14, 371-89.

Bughin J. and Vannini S. (1995) 'Strategic direct investment under unionised oligopoly.' International Journal of Industrial Organisation 13, 127-45.

Casella A. (1996) 'Free trade and evolving standard', in J.N. Bhagwati and R.E. Hudec (eds) Fair Trade and Harmonisation, Vol.1: Economic Analysis. The MIT Press.

Caves, R.E. (1996) Multinational Enterprise and Economic Analysis, second edition. Cambridge University Press.

Katrak, H. (1977) 'Multinational monopolies and commercial policy.' Oxford Economic Papers 29, 283-91.

Leahy, D. and Montagna, C. (2000) Unionisation and Foreign Direct Investment: Challenging Conventional Wisdom? Economic Journal 110, C80-C92.

Naylor R. and Santoni M. (1998) 'Wage bargaining and foreign direct investment.' Mimeo, University of Warwick.

Srinivasan T.N. (1996) 'Trade and human rights.' Economic Growth Centre D.P.No 765, Yale University.

Zhao, L. (1995) 'Cross-hauling direct foreign investment and unionised oligopoly.' European Economic Review 39, 1237-53.

Zhao, L. (1998) 'The impact of foreign direct investment on wages and employment.' Oxford Economic Papers 50, 284-301. 